\title{
Investigation on surface mounted PM machines with magnet recycling concept for hybrid electrical vehicle applications
}

\author{
Ziwei Li $^{1}$, Afef Kedous-Lebouc ${ }^{2}$, Radu Fratila ${ }^{1}$, Jerome Legranger ${ }^{1}$, Jean-Marc Dubus ${ }^{1}$, \\ Awais Ikram $^{3}$ \\ ${ }^{1}$ Valeo, Electrical Motor Equipment, 94000 Creteil - France \\ ${ }^{2}$ Univ. Grenoble Alpes, CNRS, G2Elab, Grenoble INP, F-38000 Grenoble - France \\ ${ }^{3}$ Jozef Stefan Institute Slovenia, 1000 Ljubljana -Slovenia \\ Email: ziwei.li@valeo.com
}

\begin{abstract}
The global supply of heavy rare earth magnets can become risky with the rocketing demand of rare earth permanent magnet (PM) machines. This paper focuses on the PM Alternating Current (AC) machines with magnet directreuse concept, dedicated to mild hybrid vehicle applications. The designs shall both fulfill all the requirements of the applications and the principle of simple magnet disassembly. Several SPM topologies are proposed in that way and the feasibility of implementing recycled magnets on SPMs is investigated.
\end{abstract}

Index Terms-Permanent Magnet machine, Recycling, Electrical Vehicle

\section{INTRODUCTION}

PM AC machines have gained widely use with the creation of rare earth (RE) permanent magnets, such as $\mathrm{NdFeB}$ permanent magnets. Their high efficiency as well as high energy density brings unparalleled superiority. Meanwhile the renewable energy markets are estimated to gain explosive growth in the next decades - just taking Electrical Vehicles (EVs) market as an example, Roland Berger [1] calculated that the share of all electrical powertrains will be increased from less than $2 \%$ at 2015, to around $18 \%$ at 2030, even under the assumption that conventional powertrains continuous dominance the market. Therefore, the future demand for electrical machines will be increased along with the market. Among all types of electrical machines, PM AC electrical machines are supposed to be the best candidates to meet those strict performance requirements. Thus, the demands for rare earth magnets are estimated to be sharply increased. However, on the other side, the supply of rare earth, especially heavy rare earth is not stable - the most distinguished event is 2011 rare earth crisis [2]. Due to both geographic distributions of rare earth, as well as political issues, global supply of heavy rare earth is a challenge.

Hence, there is a serious concern about heavy rare earth supply-demand balance. In order to relieve the heavy rare earth supply risk, one of the important measurements is to recycle the rare earth magnets. Recently a Horizon 2020 project in Europe was initiated. The project aims to recycle the rare earth magnets for the traction E-machines used on hybrid and pure electrical vehicles. It has envisaged three routes for the magnet recycling - direct-reuse, direct recycling and indirect recycling magnets [3], as Figure 1 shows.

This paper mainly focuses on the route of direct-reuse magnets. This concept includes both ideas of simple disassembly of magnets and utilizing recycled heavy rare earth magnets. It can be observed from Figure 1 that magnet

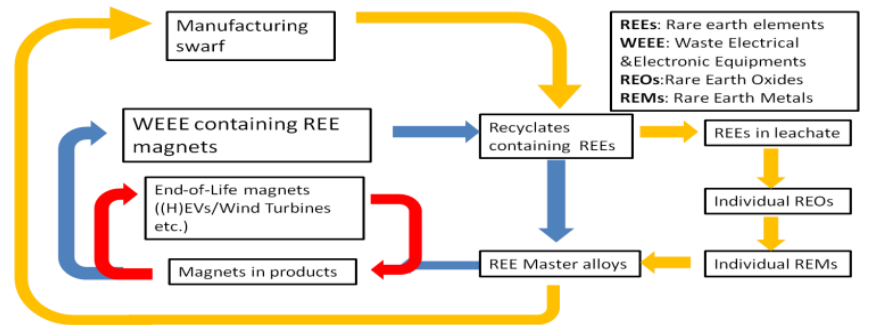

$\square$ Magnet re-use $\square$ Magnet direct recycling $\square$ Magnet indirect recycling

Fig. 1. Three recycling routes for REE permanent magnets from end-of-Life (H) EVs

direct-reuse is the shortest loop among all three routes. Once it can be realized, it will be the most economic way to recycle magnets.

However, there are many obstacles in practice. For instance, although many automotive companies recycle the components of the motor such as copper and iron, currently it is still difficult to recycle magnets, due to the hard access of the magnets, and the special characteristics of magnet. Furthermore, even if the new designs are possible, are the machines still able to fulfill the performance requirements? Therefore, the new designs for PM electrical machines must attempt to overcome all these obstacles.

The group of radial flux AC machines can be a good example for the new designs. Because currently they are the most widely used electrical machines in $(\mathrm{H}) \mathrm{EV}$ s. This group mainly includes Reluctance Machines (RM), Permanent Magnet assisted synchronous Reluctance Machines (PMasyRM), Interior Permanent Magnet machines (IPM) and Surface mounted Permanent Magnet machines (SPM). Among the group, only IPM and SPM machines need to apply large amount of heavy RE permanent magnets. Therefore, RM and PMasyRM are not in the consideration of magnets reuse framework.

From section II literature study, it is found that compare to IPM machines, SPM machines are easier to realize magnets reuse. Therefore, this paper mainly analyzes the possibility of applying SPM machines in mild hybrid electrical vehicles (MHEVs), and with magnet-direct-reuse concept.

\section{LITERATURE STUDY}

Few pioneer research have considered RE permanent magnets recycling from PM machines. For instance, a project led by Siemens named MORE [4] [5] showed the possibility of recycling RE permanent magnets from traction motors. The project had demonstrated that with customized disassembly lines, the magnets from both SPM and IPM 
electrical machines for EVs could be directly reused. Furthermore, it was found that magnets from SPM machines were easier to disassemble than IPM machines, by comparing all disassembly indexes. These indexes included the total investment of disassembly lines, ease of magnets accessing, and average magnets quality after disassembly, etc. Nevertheless, the project had never considered the benefit from the view of a new machine design for magnet reuse, as all the machines they investigated are existed products on the market.

The other project about magnet reuse was carried by $\mathrm{S}$. Hogberg, et al. [6] [7] in Denmark recently. They demonstrated a way of reusing magnets from wind turbine, from the views of machine design and disassembly process respectively. For the new machine design, they have chosen SPM machine for their fundamental design as well. The idea was to use segmented magnets with standard size. The magnet poles were then formed by these magnet segments with massive glue. Considering the severe working environment of wind turbines, the magnet poles could be covered by stainless steel containers. Then for the disassembly process, they have mainly chosen thermal treatment for glue melting and magnet demagnetization. The heating temperature was well controlled around the curie point of the magnet. The degradation of the magnets was also studied. They found by choosing proper magnet coating, magnets degradation after thermal treatment could be well limited. For sintered $\mathrm{NdFeB}$ magnets, the best coating to prevent degradation was $\mathrm{NiCu}+$ Epoxy.

The main problem of this design was the reduced average torque due to the active space occupied by the massive glue. In order to compensate the lost torque, they had to overdimension the machine. For this case, the length of the machine was increased by $\mathbf{3 . 5 \%}$ comparing to the original machine. After all, this design was for wind turbine application, which characterizations were low speed and low ambient temperature. While for $(\mathrm{H}) \mathrm{EV}$ applications, the machines need to be operated at considerably high speed and critical high temperature. Thus SPM may not entirely suit for the working environment.

Nevertheless, with the former studies on magnet-directreuse, SPM machines could still be a good starting point for the research, due to their simple magnets disassembly and well known characteristics.

\section{Methodology}

The requirements of electrical machines for mild $\mathrm{HEV}$ are rigorous. Some key constraints are listed in Table I. In addition, due to the mass production, special designs have to be implemented to maintain the low cost.

TABLE I

REQUIREMENTS OF ELECTRICAL MACHINES FOR MHEV

\begin{tabular}{|l|c|l|c|}
\hline Requirements & Value & Requirements & Value \\
\hline Outer diameter(mm) & $<200$ & $\begin{array}{l}\text { Current } \\
\text { limitations for } \\
\text { drive unit(A) }\end{array}$ & $<500$ \\
\hline Axial length $(\mathrm{mm})$ & $<100$ & Max speed(rpm) & $>15000$ \\
\hline Operating temperature $\left({ }^{\circ} \mathrm{C}\right)$ & $80 \sim 180$ & $\begin{array}{l}\text { Full load max } \\
\text { torque(N.m)\& } \\
\text { Torque ripple }\end{array}$ & $\begin{array}{l}>50 \& \\
\text { very low }\end{array}$ \\
\hline DC supply voltage(V) & $42-52$ & Max power(kW) & 14 \\
\hline
\end{tabular}

For instance, dual three-phases winding configuration is a good trade-off because it can divide the load of each inverter bridge into half. Thus, under the same output power, it is possible to use previous inverter components which drive small motors. In addition, one more advantage of multiplephases configuration is their higher fault tolerance compared to normal 3-phase configuration [8].

Due to the critical thermal condition, rectangular coil is the priority choice. Compare to random wound round coils, rectangular coils always have larger filling factor. The exposed surface of rectangular coils is also larger than round coils. Thus the cooling factor is better for rectangular coils. But this in turn leads to additional constraints on stator slot comparing to random wound round windings, as it can no longer "randomly" wound the coils.

There is one more mechanical constraint from SPM machines - in simulations, the minimum airgap length have to take into account both real airgap length and the thickness of a retention sleeve. This retention sleeve is used for fixing the magnet on the rotor surface. As the sleeves are normally made by carbon fiber or polyester, their permeability can be equivalent to air. R. Benlamine, et al [9] have investigated the relationship between sleeve thickness and machine constraints. They found the thickness is proportional to the rotor diameter, maximum rotation speed and magnet mass density. Therefore, based on our constraint inputs, $1.5 \mathrm{~mm}$ for minimum sleeve thickness is reasonable. With $0.5 \mathrm{~mm}$ real airgap length, the total equivalent airgap thickness thence is $2 \mathrm{~mm}$.

With the assumptions above, the performance comparisons can be carried out under the same machine dimensions, including the same outer diameter and same stack length.

TABLE II

MATERIAL CHARACTERISTICS OF EACH COMPONENT

\begin{tabular}{|c|c|c|}
\hline $\begin{array}{c}\text { Machine } \\
\text { component }\end{array}$ & Material & Properties \\
\hline $\begin{array}{c}\text { Iron cores } \\
\text { (rotor, } \\
\text { stator) }\end{array}$ & $\begin{array}{c}0.35 \mathrm{~mm} \\
\mathrm{SiFe}\end{array}$ & $1.65 \mathrm{~T}, 5000 \mathrm{~A} / \mathrm{m}$ \\
\hline Magnets & $\mathrm{NdFeB}$ & $\begin{array}{c}\text { Remanence flux density @ } 80{ }^{\circ} \mathrm{C}: 1.14 \mathrm{~T} \\
\text { Remanence temp coefficient: }-0.1 \% /{ }^{\circ} \mathrm{C} \\
\text { Coercivity @ } 80{ }^{\circ} \mathrm{C}: 1.5 \mathrm{e} 6 \mathrm{~A} / \mathrm{m} \\
\text { Electrical conductivity: } 0.67 \mathrm{MS} / \mathrm{m}\end{array}$ \\
\hline Windings & Copper & $5.96 \times 10^{\wedge} 7 \mathrm{~S} / \mathrm{m}$ \\
\hline
\end{tabular}

Besides, the materials used for all the machines are the same. They are shown in Table II.

The performances comparison mainly focuses on torque characteristics, magnets demagnetization, efficiency, and a simple thermal study. Besides the SPM machine designs with virgin magnets, the performances of SPMs with magnet-reuse concept are discussed at the end.

\section{RESULT}

The simulation results were carried out by Finite Element Analysis (FEA). A lump circuit was coupling with the FEM model. In the circuit, only sinusoidal current sources were applied. As Ampere's circuit law said flux density is directly link to the current, all the electromagnetic performances of steady state can be thus derived by the current. However, in reality, the power supply is always voltage source with proper control loop. This will bring 
some amount of harmonics in the current waveform. Since our focus is on the machine performances itself, voltage simulation is out of the scope.

\section{A. Poles, slots and turns selections}

The first decision for the design is number of poles. The pole number $p$ is constrained by two conditions - inverter switch frequency and end winding length. For HEV applications, there is a fixed maximum switch frequency $f O$ of machine drive. The electrical frequency $f e$ of the machine is limited by (1). Besides, the relation between $f e$ and $p$ is shown by (2).

$$
\begin{gathered}
10^{*} f e<f 0 \\
f e=N^{*} p / 120
\end{gathered}
$$

where $N$ is the maximum rotation speed. Thus, with $N$ and the given $f O$ which is $10 \mathrm{kHz}$ in our case, the upper limit of $p$ can be easily obtained which equals to 10 in this case.

Next, the end winding length setup the lower limit of pole number. Since with lower $p$, the end winding is higher because turns have to across longer pole pitch. With limited axial space for HEV application, the height of end turns is strictly constrained. Thus, the minimum $p$ is 8 for this case. At the end, $p$ can only be 8 and 10. But for the curiosity of low-pole-number machine performances, it is feasible to take one machine example with 6 poles.

With the assumed pole number, the slot number can be decided consecutively. The upper limitation for the slot number is the teeth width. Due to flux saturation and its mechanical strength, the teeth width cannot be too small. Thus, based on the fixed stator external diameter, the smallest teeth width can be obtained, Thus, the slot number have to be lower than 90 .

With 1, 1.5 and 2 slots/pole/phases (SPP) assumptions, all the possibilities of pole/slot combinations are shown in Table III.

TABLE III

SPM POLE/SLOT COMBINATIONS WITH DUAL-THREE PHASES RECTANGULAR DISTRIBUTED WINDINGS

\begin{tabular}{|c|c|c|c|c|}
\hline $\begin{array}{c}\text { Machine } \\
\text { Number }\end{array}$ & Poles & SPP & Total slots & Turns/phases \\
\hline 1 & 6 & 1 & 36 & 18 \\
\hline 2 & 8 & 1 & 48 & 16 (full pitch) \\
\hline 3 & 8 & 1 & 48 & 16 (short pitch) \\
\hline 4 & 8 & 1.5 & 72 & 12 \\
\hline 5 & 8 & 1.5 & 72 & 24 \\
\hline 6 & 8 & 2 & 96 & 16 \\
\hline 7 & 10 & 1 & 60 & 15 \\
\hline 8 & 10 & 1.5 & 90 & 15 \\
\hline
\end{tabular}

The final filter is coil turns number. It needs to be clarified that only distributed winding is considered. As the application is tend to be high speed, it would be better to reduce the MMF harmonics in order to decrease the iron losses. Distributed windings contain low total harmonic distortion (THD), thus they can effectively limit iron losses and magnet losses during high speed operation.

Then coil turns number per phase $n$ can be chosen. The number is limited by maximum output power $P_{\max }$ and average output torque $T$. The upper limit is constrained by $P_{\max }$, where $P_{\max } \propto 1 / n$, the lower limit is constrained by $T$, where $T \propto n$. With some trial-and-error calculation, a reasonable range for $n$ is between 14 and 16 .
It is worth to mention that for the machines with 8 poles, windings are not only full pitch, but also can be short pitch.

There are some advantages for short pitch windings, such as lower THD, and lower end winding length comparing to full pitch windings. But they also reduce the fundamental value of MMF, which result in lower torque. All the winding factors of full pitch machines are 1, while the winding factor of short pitch is 0.933 in this case.

Therefore, with these condition filters, only machine number 2, 3 and 7 are able to fulfill all constraints. The following performance comparisons were carried out only among these four machines.

\section{B. Torque characterizations}

With the known pole number $p$, slot number $s$ and turn number per phase $n$, the FEA simulation can be carried. In order to obtain accurate results, there were some pre-set for the transient study simulations - The time step have to be small enough to see the full period of torque ripples; The meshes have to be set properly for different components, as Figure 2 shows.

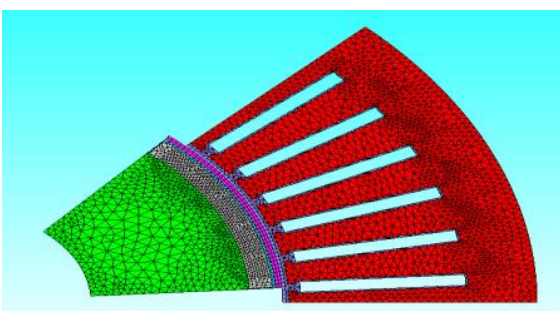

Fig. 2. The mesh of a $2 \mathrm{D}$ model, e. g. 8 poles machine

There are some other assumptions for the models. As [10] suggested, the magnet thickness is better to be larger than 2 $\mathrm{mm}$, which is able to provide proper demagnetization withstand capability. In our case, a breadloaf style magnet was used. For security, the thickest part of the magnet was $3 \mathrm{~mm}$ for all models. The magnet was applied parallel magnetization with anisotropic characteristics. The regular operation temperature was $80{ }^{\circ} \mathrm{C}$. More details about the magnet can be found in the Demagnetization Analysis section.

Finally for all machines, tooth tip height and slot opening share the same values and always remain constant. Their impacts to the performance are not discussed in this paper.

With the same current input provided by inverter system, the maximum average torque was derived for each machine. As the torque value is calculated for constant torque region, the rotation speed of this operation point was relatively low.

From the opinion of Y. Pang et al. [11] and J. Goss et al. [12] there is an optimal split ratio for torque/copper losses ratio. The split ratio equals to $D O / D s$, where $D O$ denotes the stator outer diameter and $D s$ denotes the stator bore diameter. In our case, $D O$ was fixed, thus only $D s$ was changing.

During the optimization process, for each model, the copper losses have to be kept the same. Thus, the slot shape for each machine was the same. Meanwhile the filling factor of the slot was maintained in a reasonable range. In addition, during split ratio optimization, the area of the magnet was kept maximum. Simply speaking, it was a magnet ring that covers the rotor core. Finally, iron losses and their impact were ignored in this split ratio study.

With the assumptions above, the torques of SPM machines can be calculated by equation (3), 


$$
\mathbf{T}=2[\Psi \mathbf{m} \cdot \text { I. } \sin (\theta)+(\mathbf{L d}-\mathbf{L q}) \cdot \text { I. } \cos (\theta) . \text { I. } \sin (\theta)]
$$

where $\theta$ is the angle between phase current and d-axis. For SPM machines, normally without saturation, $L d=L q$. Thus the maximum torque current appears at $\theta=90^{\circ}$. Afterwards the parametric study of spit ratio can be carried out. The results are shown in Figure 5. Here torque is expressed in per unit value. As [11] indicated, the pole number and airgap flux density have influences to the optimal split ratio.

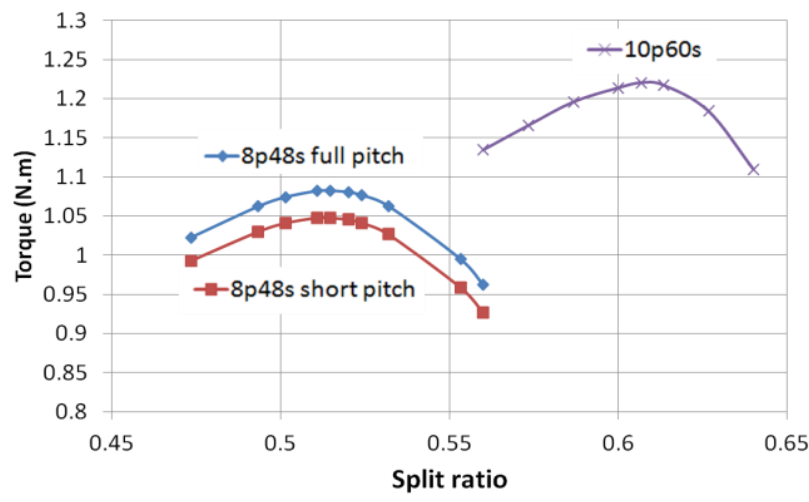

Fig. 3. Split ratio curves for the four machines

From Figure 3, with the increase of pole number, the optimal split ratio is also increasing. Due to the fact that higher split ratio results in smaller yoke thickness. Meanwhile higher pole number results in smaller pole pitch, which causes less magnetic saturation for the same thickness of the yoke.

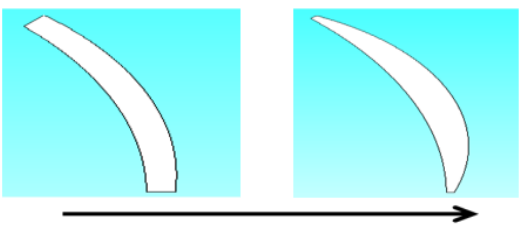

Sharpness increasing

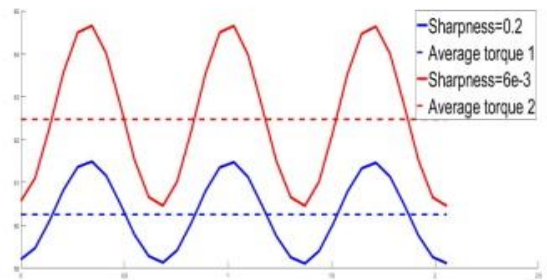

Fig. 4. Torque ripple control by magnet shaping

The next step is torque ripple control. Only the torque ripple during constant torque range was studied. The main idea was to use breadloaf shape magnets, as [13] described. The torque ripple can be reduced with the increasing of magnet sharpness, as Figure 4 shows. The sharpness rate was calculated by the magnet reduced fringe length over maximum magnet thickness, which is $3 \mathrm{~mm}$. Meanwhile, the average torque was reduced as well by the increase of magnet sharpness. Thus, it was necessary to make a compromise between torque amplitude and torque ripples. It was found that without sacrificing the coverage of the magnet, the torque ripple can be controlled in an acceptable level.

Finally, the torque speed curves can be obtained by current and voltage limitations from the inverter system, as Figure 5 shows. It can be observed that the characteristics of both 8 poles machines are very similar. 10 poles machine has the highest margin for both torque and corner speed. But it also indicated that the short circuit (SC) current of 10 poles machine can be relatively large, due to its lower number of turns per phase compare to 8 poles machines. This may result in serious thermal problem, which is discussed in Thermal Conditions section.

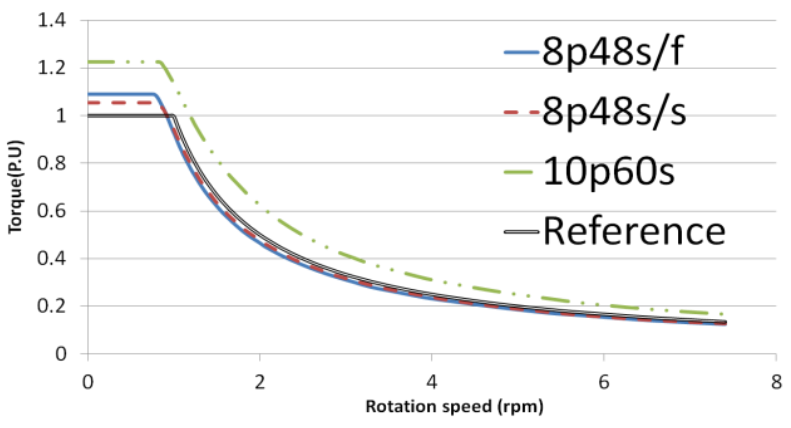

Fig. 5. Torque speed curves of the four machines

\section{Magnet demagnetization analysis}

Due to the strong demagnetization fields during flux weakening and short circuit conditions, as well as serious high temperature environment, the demagnetization of the magnets has to be taken special care. Thus, demagnetization analysis and magnet eddy current analysis were carried out thence.

Two critical demagnetization scenarios were studied - S1, double SC current amplitude with regular temperature $80^{\circ} \mathrm{C}$; $\mathrm{S} 2$, regular SC current with high temperature $180^{\circ} \mathrm{C}$. The demagnetization level of each machine was evaluated. The fully demagnetized areas are shown in Figure 6 and Table IV. Double SC current amplitude can be presumed as overshoot SC current during transient state. But specific transient moment is out of the scope.

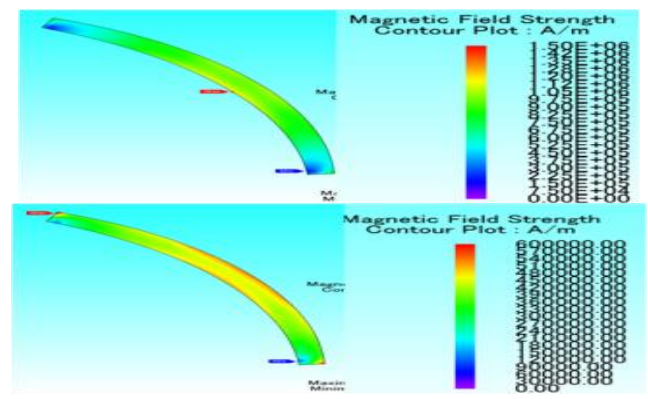

Fig. 6. Visualized demagnetization level, e.g. machine 7, expressed in magnetic field strength $(\mathrm{A} / \mathrm{m})$ : Upper S1: double SC current, $80^{\circ} \mathrm{C}$, top speed, demagnetization limit is $1.5 \mathrm{e} 6 \mathrm{~A} / \mathrm{m}$; Lower $\mathrm{S} 2$ : regular SC current, $180^{\circ} \mathrm{C}$, top speed, demagnetization limit is $6 \mathrm{e} 5$ $\mathrm{A} / \mathrm{m}$.

It can be observed that all the machines have acceptable anti-demagnetization capability. Compare to Scenario 1, all machines have less demagnetization margin at Scenario 2. From Figure 6, the areas which suffer high risk of demagnetization are the middle and fringe corner. Thus, sometimes the sharpness of the magnet cannot be too large, due to the ease of demagnetization at the fringe corner.

Besides demagnetization, the magnet safety faces another threat which is eddy current. Too strong eddy current inside magnet can result in magnet overheat, which degrades its coercivity. 
TABLE IV

PERMANENT DEMAGNETIZED AREA PERCENTAGE OF EACH MACHINE FOR TWO DEMAGNETIZED SCENARIOS

\begin{tabular}{|c|c|c|}
\hline Machine Number & S1 & S2 \\
\hline 2 & 0 & 0 \\
\hline 3 & 0 & 0 \\
\hline 7 & 0 & $0.3 \%$ \\
\hline
\end{tabular}

The magnet eddy current can be hazardous at two scenarios - S1, full load operation, which has strong airgap magnetic field that induces large eddy current; S2, high speed operation, which high frequency of the airgap magnetic field can induce strong eddy current as well. Therefore, these two scenarios were simulated.

It needs to be highlighted that the simulations have to be carried out in 3D models. Because the magnets total resistances in 2D models are much smaller than 3D models.

The $3 \mathrm{D}$ simulation results at $80{ }^{\circ} \mathrm{C}$ are shown in Table V.

TABLE V

MAGNET EDDY CURRENT DENSITY AND TOTAL JOULE LOSSES UNDER FULL LOAD AND TOP SPEED SC SCENARIOS

\begin{tabular}{|c|c|c|c|c|}
\hline \multirow{2}{*}{$\begin{array}{c}\text { Machine } \\
\text { number }\end{array}$} & \multicolumn{2}{|c|}{$\mathrm{S} 1$} & \multicolumn{2}{c|}{$\mathrm{S} 2$} \\
\cline { 2 - 5 } & $\mathrm{Jmax}\left(\mathrm{A} / \mathrm{mm}^{2}\right)$ & $\mathrm{P}_{\text {Joule }}(\mathrm{W})$ & $\operatorname{Jmax}\left(\mathrm{A} / \mathrm{mm}^{2}\right)$ & $\mathrm{P}_{\text {Joule }}(\mathrm{W})$ \\
\hline 2 & 0.33 & 6.1 & 1.46 & 100 \\
\hline 3 & 0.32 & 6.2 & 1.48 & 105 \\
\hline 7 & 0.29 & 6.7 & 1.50 & 170 \\
\hline
\end{tabular}

From Table V, it can be observed that all machines have relatively small magnet Joule losses. Thanks to the wide gap between rotor and stator, the flux density is generally weak. Besides, Machine 2 and 3 have least overheat risk. Short circuit scenario is much worse than full load scenario. Although the SC current of Machine 7 is much higher than Machine 2 and 3, and the electrical frequency of 10 poles machine was also the highest, the Joule losses of Machine 7 were not much higher than Machine 2 and 3. Thanks to the smallest size of the magnet of Machine 7, it effectively reduced the magnet eddy currents [14].

\section{Efficiency}
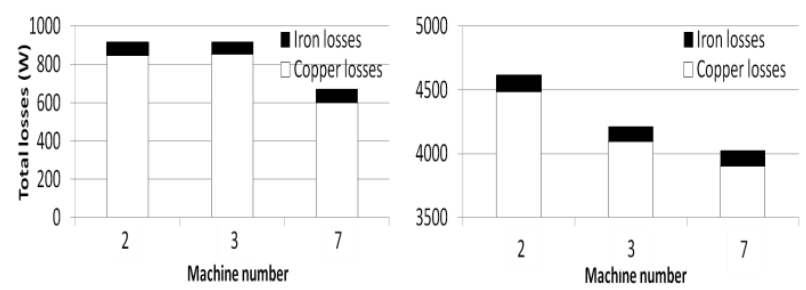

Fig. 7. Left P1, constant load losses at corner speed; Right P2, full load losses at corner speed.

Copper losses and iron losses are taken into account in the efficiency. Copper losses were simply used Joule's Law to calculate. However, the skin effect and proximity effect of the coil due to AC currents were ignored here. Iron losses were calculated by Bertotti's model [15]. The losses are comprised of hysteresis losses, eddy current losses and excess losses.

The efficiencies of two operation points were analyzed. They were point 1 , constant load at corner speed; point 2, full load at corner speed. The results are shown in Figure 7 and Table VI.
TABLE VI

EFFICIENCY AT TWO DIFFERENT OPERATION POINTS

\begin{tabular}{|c|c|c|}
\hline Machine Number & P1 & P2 \\
\hline 2 & $86 \%$ & $72 \%$ \\
\hline 3 & $87 \%$ & $75 \%$ \\
\hline 7 & $90 \%$ & $79 \%$ \\
\hline
\end{tabular}

It can be observed that the efficiency of machine 7 is the highest among all machines. This indicates that when copper losses dominate all losses, the efficiency is rising with the increase of pole number. However, due to the nature of low voltage supply, the efficiencies of all machines are not supreme.

\section{E. Thermal conditions}

In this paper only stator thermal condition was analyzed. A simple equivalent thermal circuit was used for temperature calculation. A standard macro thermal equivalent resistance was obtained from measurements in advance.

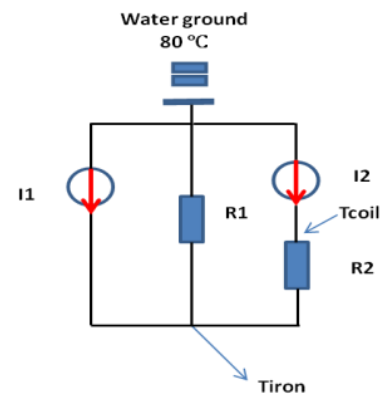

Fig. 8. Stator thermal equivalent circuit

Then with the target machine dimensions, our own macro thermal equivalent resistance can be derived. Then two local thermal resistances were derived from equivalent resistance respectively - iron-water resistance $\mathrm{R} 1$ and coil-iron resistance R2, as Figure 8 shows. In the figure, I1 denotes iron losses, I 2 denotes copper losses. All losses can be seen as current sources. As the machine is water cooled, the water temperature is $80^{\circ} \mathrm{C}$ constant. Therefore, the water in the equivalent circuit can be seen as ground.

TABLE VII

COIL TEMPERATURES UNDER CONSTANT LOAD AND TOP SPEED SHORT CIRCUIT OPERATIONS

\begin{tabular}{|c|c|c|}
\hline Machine Number & $\mathrm{S} 1\left({ }^{\circ} \mathrm{C}\right)$ & $\mathrm{S} 2\left({ }^{\circ} \mathrm{C}\right)$ \\
\hline 2 & 174 & $>200$ \\
\hline 3 & 175 & $>200$ \\
\hline 7 & 147 & $>300$ \\
\hline
\end{tabular}

With the known iron and copper losses, the iron and coil temperatures can be calculated respectively. While comparing to coil temperature, iron temperature is usually much lower. Moreover, iron core can endure much higher temperature than coil. Therefore, only coil temperatures were discussed. Two extreme scenarios were also analyzed, which were S1, constant load operation and S2, top speed short circuit operation. The results are shown in Table VII.

In Table VII, if the coil temperature limit is set as $200{ }^{\circ} \mathrm{C}$, then in Scenario 1 all machines remain some margins. While the SC thermal conditions of all machines are in bad situations, especially for 10 poles machine.

Therefore, after the rough analyze, thermal conditions for all the SPM machines are not acceptable for SC condition. 
This is another obstacle for magnet reuse design. However, as the equivalent circuit was quite simple, the heating dissipation from stator bore was not considered, and the end winding resistance might be exaggerated. The coil temperature might be overestimated thence. Nevertheless, it only gave a hint for the final conclusions.

\section{F. Performances degradation by magnet-reuse design}

Here two magnet reuse strategies were implemented. First one was to use magnet segments method as [6] described. The active length of the machine was reduced due to glue space. Here we assume the same length reduction rate of [6], which is $3.5 \%$. Therefore, the maximum torque of each machine is shown in Table VIII. It can be observed that the torque reduction is almost linear with active length reduction. Machine 3 cannot fulfill the torque requirement after using the new design.

TABLE VIII

MAX AVERAGE TORQUES OF TWO MAGNETS RECYCLING STRATEGIES

\begin{tabular}{|c|l|c|c|}
\hline $\begin{array}{l}\text { Machine } \\
\text { Number }\end{array}$ & $\begin{array}{l}\text { Maximum } \\
\text { average torque } \\
\text { (P.U.) of } \\
\text { original design }\end{array}$ & $\begin{array}{l}\text { Maximum } \\
\text { average torque } \\
\text { (P.U.) with } \\
\text { reduced active } \\
\text { length }\end{array}$ & $\begin{array}{l}\text { Maximum } \\
\text { average torque } \\
\text { (P.U.) with } \\
\text { recycled magnets }\end{array}$ \\
\hline 2 & 1.10 & 1.05 & 0.85 \\
\hline 3 & 1.02 & 0.98 & 0.78 \\
\hline 7 & 1.18 & 1.12 & 0.89 \\
\hline
\end{tabular}

The second strategy was to use recycled heavy RE magnet from other recycling routes. Here some experiments were carried out. The Spark Plasma Sintering (SPS) were implemented to recover magnet powder to recycled magnets. The magnet powder was obtained from an anisotropic bonded magnet which remanence flux $(\mathrm{Br})$ is $0.9 \mathrm{~T}$. Then with several attempts of different sintering temperatures and sintering holding time, the highest $\mathrm{Br}$ that obtained was $0.87 \mathrm{~T}$. Therefore, with the property of this recycled magnet, the new torque results are shown in Table VIII.

It can be observed that no machine, without any topology modification, is able to fulfill the torque requirement after using recycled magnets. To maintain the torque amplitudes, it is necessary to increase the volume of the magnet, which indicates different split ratios and different magnet thickness. Nevertheless, with the improvement of recycled magnet quality, the machine may still meet the requirements.

Certainly, it does not mean that there is no any advantage by using magnet reuse design. For instance, the segmented magnet can effectively reduce magnet eddy currents.

\section{CONCLUSION}

From all the analyses above, it can be clearly known the pros and cons of each machine. 10 poles machine has too large short circuit current, which results in serious thermal problem. 8 poles short pitch machine has too small torque margin, which is impossible for reuse concept. Therefore, only 8 poles machine with full pitch is the best candidate for magnet-direct-reuse design. However, for all SPM machines, the thermal conditions are not optimistic; the efficiency has no superiority; the demagnetization margin of high temperature scenario is small, and let alone using expensive materials to fix magnets. These are the obstacles that have to be overcome once SPM machines are apply on MHEV, as well as magnet-reuse concept.

Nevertheless, this paper only shows a methodology of estimating the feasibility of magnet-reuse design. With the variation of applications, the conclusions might be different. In this paper the main obstacles of SPMs application with magnet recycling concepts are investigated and highlighted. It is necessary to study other radial flux machines in the future, such as IPM machines. Meanwhile, new rotor manufacturing methods which enable easy magnet disassembly might be used. Moreover, with the quality improvement of recycled heavy RE magnet, the reuse concept may become more and more promising.

\section{ACKNOWLEDGMENT}

The research leading to these results has received funding from European Communitys Horizon 2020 Programme ([H2020/20142019)] under Grant Agreement no. 674973 (MSCA-ETN DEMETER). This publication reflects only the authors view, exempting the Community from any liability. Project website: http://etn-demeter.eu/.

\section{REFERENCES}

[1] S. Arnoud, S. Thomas, P. Walter, B. Markus, "Integrated fuels and vehicles roadmap to 2030+", Roland Berger, April 2016.

[2] K. Bourzac, "The rare-earth crisis. MIT Technology Review. http://www.technologyreview.com/featuredstory/423730 the-rare-earth-crisis/" 2011.

[3] K. Binnemans, P. T. Jones, B. Blanpain, T. V. Gerven, Y. Yang, A. Walton and M. Buchert, "Recycling of rare earths: a critical review," vol.51, p 1-22, Journal of Cleaner Production, 2013.

[4] U. Bast, F. Treffer, C. Thürigen, T. Elwert, F. MarscheiderWeidemann, "Recycling von Komponenten und strategischen Metallen aus elektrischen Fahrantrieben," Recycling und Rohstoffe, Bd, vol 5, 2014.

[5] T. Klier, F. Risch, J. Franke, "Disassembly, recycling, and reuse of magnet material of electric drives. In : Assembly and Manufacturing (ISAM),” p. 88-9, IEEE International Symposium, 2013.

[6] S. Hogberg, T. S. Pedersen, B. B. Jensen, N. Mijatovic, J. Holboll, "Direct Reuse of Rare Earth Permanent Magnets -Wind Turbine Generator Case Study,"ICEM, 2016.

[7] S. Hogberg, J. Holboll, N. Mijatovic, B. B. Jensen, F. B. Bendixen, "Direct Reuse of Rare Earth Permanent Magnets-Coating Integrity," vol. 53, no. 4, p. 1-9, IEEE Transactions on Magnetics, IEEE, 2016.

[8] M. T. Abolhassani and H. A. Toliyat, "Fault tolerant permanent magnet motor drives for electric vehicles," in Proc. IEEE Int. Electr. Mach. Drives Conf. (IEMDC), pp. 1146-1152, May 2009,

[9] R. Benlamine, T. Hamiti, F. Vangraefschèpe, and D. Lhotellier, "Electromagnetic, mechanical and thermal analysis of a high-speed surface-mounted PM machine for automotive application. In Electrical Machines," XXII International Conference (ICEM), pp. 1662-1667, IEEE. 2016

[10] G. J. Li, and Z. Q. Zhu, "Demagnetization of modular surface mounted permanent magnet machines." In Electrical Machines, XXII International Conference (ICEM), pp. 702-708, IEEE. 2016.

[11] Y. Pang, Z. Q. Zhu, and D. Howe, "Analytical determination of optimal split ratio for permanent magnet brushless motors." IEE Proceedings-Electric Power Applications vol. 153, no 1, p. 7-13. 2016.

[12] J. Goss, R. Wrobel, P. Mellor and D. Staton, "The design of AC permanent magnet motors for electric vehicles: A design methodology." In Electric Machines \& Drives Conference (IEMDC), pp. 871-878, IEEE International, May 2013.

[13] K. I. Laskaris, A. G. Kladas, "Permanent-magnet shape optimization effects on synchronous motor performance." IEEE Transactions on Industrial Electronics, vol. 58, no 9, p. 3776-3783, 2011.

[14] B. Aslan, , E. Semail, , J. Legranger, "General Analytical Model of Magnet Average Eddy-Current Volume Losses for Comparison of Multiphase PM Machines With Concentrated Winding." IEEE Transactions on Energy Conversion, vol. 29, no 1, p. 72-83, 2014.

[15] G. Bertotti, "General properties of power losses in soft ferromagnetic materials", IEEE Transactions on magnetics, vol. 24, No. 1, pp.621630, January, 1988. 